\title{
Effects of milk replacer meal size on feed intake, growth performance, and blood metabolites and hormones of calves fed milk replacer with or without butyrate ad libitum: A cluster-analytic approach
}

\author{
Morteza H. Ghaffari, ${ }^{1}$ Harald M. Hammon, ${ }^{2 *}$ Dörte Frieten, ${ }^{3} \dagger$ Caroline Gerbert, ${ }^{4}$ Georg Dusel, ${ }^{3}$ \\ and Christian $\mathrm{Koch}^{4 *}$ \\ ${ }^{1}$ Institute of Animal Science, Physiology Unit, University of Bonn, 53115 Bonn, Germany \\ ${ }^{2}$ Institute of Nutritional Physiology "Oskar Kellner," Leibniz Institute for Farm Animal Biology (FBN), 18196 Dummerstorf, Germany \\ ${ }^{3}$ Department of Life Sciences and Engineering, University of Applied Sciences Bingen, 55411 Bingen am Rhein, Germany \\ ${ }^{4}$ Educational and Research Centre for Animal Husbandry, Hofgut Neumuehle, 67728 Münchweiler an der Alsenz, Germany
}

\begin{abstract}
This study intended to classify ad libitum-fed calves according to their milk replacer (MR) meal size using the K-means clustering approach. This study aimed to investigate the effects of MR meal size on feed intake, growth performance, and blood metabolic and hormones of ad libitum MR-fed calves. German Holstein calves (16 male and 16 female) were studied from birth until d 77 of age. All calves received first colostrum $(2.5 \mathrm{~kg})$ milked from their dams within 2 $\mathrm{h}$ after birth. Subsequent colostrum meals (subsequent 4 meals until $2.5 \mathrm{~d}$ of age; 2 meals/d) and MR (125 g of powder $/ \mathrm{L} ; 21.7 \%$ crude protein, $18.6 \%$ crude fat) were fed ad libitum by teat bucket until d $10 \pm 2$ of age. Afterward, calves were housed in group pens with automatic feeders for MR (maximum of $25 \mathrm{~L} / \mathrm{d}$ ) and concentrate from $10 \pm 3 \mathrm{~d}$ of age. Half of the calves received MR supplemented with butyrate to improve growth performance. Milk intake was stepped down to $2 \mathrm{~L} / \mathrm{d}$ from wk 9 to 10 , and $2 \mathrm{~L} / \mathrm{d}$ of MR were offered until the end of the study. On d 1,2,4, and 7, and then weekly until wk 11 of age, blood samples were collected for measurement of metabolites and hormones related to energy metabolism and growth. The K-means cluster analysis on the MR meal size data collected from the automatic feeder resulted in 3 clusters $(\mathrm{n}=14, \mathrm{n}$ $=12$, and $\mathrm{n}=6)$. Two clusters with a sufficient cluster size $(n=14$ and $n=12)$ were included for further statistical analysis using repeated measures mixed-model ANOVA. In both clusters, butyrate supplementation was equally distributed and failed to affect a difference
\end{abstract}

Received April 1, 2020.

Accepted December 9, 2020.

*Corresponding authors: c.koch@neumuehle.bv-pfalz.de and hammon@fbn-dummerstorf.de

$\dagger$ Present address: Thünen Institute of Organic Farming, 23847 Westerau, Germany. in MR meal size. Cluster 1 showed calves with higher MR meal size (HI; $2.2 \pm 0.11 \mathrm{~L} /$ visit of MR) and cluster 2 with lower meal size $(\mathrm{LO} ; 1.8 \pm 0.07 \mathrm{~L} /$ visit of MR) supplemented MR without (HIB-; $\mathrm{n}=6$; LOB-, $\mathrm{n}=7$ ) or with $0.33 \%$ calcium-sodium butyrate (HIB+; $\mathrm{n}=6 ; \mathrm{LOB}+, \mathrm{n}=7)$. Dry matter intake of MR did not differ between $\mathrm{HI}$ and LO, but intakes of concentrate and total dry matter tended to be greater in $\mathrm{HI}$ than in $\mathrm{LO}$ and increased more distinctly in HI than in LO at the end of the study. The average daily gain $(\mathrm{g} / \mathrm{d})$ was greater in $\mathrm{HI}$ than in LO. Plasma concentrations of total protein $(\mathrm{g} / \mathrm{L})$, albumin $(\mathrm{g} / \mathrm{L})$, glucose $(\mathrm{mmol} / \mathrm{L})$, urea $(\mathrm{mmol} / \mathrm{L})$, insulin $(\mu \mathrm{g} / \mathrm{L})$, and glucagon $(\mathrm{ng} / \mathrm{L})$ were higher, and the concentrations of insulin-like growth factor I tended to be higher, in HI than in LO calves. Plasma $\beta$-hydroxybutyrate was higher in LO than in $\mathrm{HI}$ at $\mathrm{d} 63$ and lower in calves fed MR with butyrate at d 77. In conclusion, clustering analysis discriminates 2 main groups of calves with different MR meal size and indicates an effect of MR meal size on solid feed intake, growth performance, and metabolic changes.

Key words: calf, cluster analysis, ad libitum feeding, meal size

\section{INTRODUCTION}

Automatic milk or milk replacer (MR) feeders can be programmed to feed calves for free-access feeding and have been advertised as a natural calf-rearing method that allows calves to express natural feeding patterns in terms of the amount, frequency, and duration of milk meals (Appleby et al., 2001; Jensen and Holm, 2003; Borderas et al., 2009). Previous findings indicate that neonatal calves have a large ability to tolerate abomasum distension, and they can ingest large amounts of milk up to $6.8 \mathrm{~L} /$ meal without risk of milk entering the rumen (Ellingsen et al., 2016). A compromised starter feed intake in calves due to feeding large amounts of 
milk or MR has been observed in some studies (Jasper and Weary, 2002; Kristensen et al., 2007; Davis Rincker et al., 2011), but not in others (Maccari et al., 2015; Schäff et al., 2016; Korst et al., 2017). However, in the intensive milk or MR feeding program, more attention must be paid to weaning (Meale et al., 2017; Mirzaei et al., 2020). Reducing milk or MR feeding too fast or too early may result in impaired growth and development during the weaning process (Mirzaei et al., 2018; Welboren et al., 2019; Parsons et al., 2020).

Findings in intensive or ad libitum milk- or MR-fed calves suggest a positive effect on body growth (Maccari et al., 2015; Korst et al., 2017; Jafari et al., 2020), anabolic metabolism, and organ development (Geiger et al., 2016; Frieten et al., 2017; Soberon and Van Amburgh, 2017). An intensive milk-feeding program affects glucose, fat, and protein metabolism, enhances plasma insulin and IGF-I release, and promotes the postnatal somatotropic axis in preweaning calves (Schäff et al., 2016; Frieten et al., 2017, 2018). Furthermore, milk meal size and feeding frequency affect metabolic and endocrine traits related to nutrient supply and growth in neonatal and veal calves, indicating an improved IGF-I status in blood plasma with an elevated milk feeding frequency (Kaufhold et al., 2000; Nussbaum et al., 2002). Intensive milk feeding improves animal welfare by fewer signs of hunger (de Passillé, 2001; Miller-Cushon and DeVries, 2015; Gerbert et al., 2018) and contributes to long-lasting effects on later milk production (Van Amburgh and Soberon, 2013; Korst et al., 2017) as well as metabolic profiling (Kenéz et al., 2018). Furthermore, feeding calves with unlimited amounts of MR has been shown to improve intestinal growth and absorptive capacity during the preweaning period (Schäff et al., 2018; Koch et al., 2019).

Several studies have shown interindividual variability in milk intake among dairy calves before and after weaning (Rosenberger et al., 2017; Dennis et al., 2018), which likely contributes to the interindividual variability in weight gains (e.g., $0.1-1.6 \mathrm{~kg} / \mathrm{d}$; Soberon et al., 2012) or weaning age (Neave et al., 2019) observed across studies. Also, interindividual variability was reported in feeding behavior such as drinking speed and the number of rewarded and unrewarded visits to the milk feeder among preweaning calves (de Passillé and Rushen, 2012; Korst et al., 2017; Gerbert et al., 2018). Characteristics such as low vitality, strong drinkers, and exploratory-active were associated with measures of feeding behavior, feed intake, and growth, especially during the preweaning period (Neave et al., 2019). Therefore, with a growing movement toward rearing calves using intensive or unrestricted milk feeding, there are more opportunities to manage calves at the individual level.
To reveal these individual differences, cluster analysis (an unsupervised machine learning method) is an effective method for identifying groups based upon similarity in multiple characteristics simultaneously (Borcard, 2011) and has been used in a variety of dairy cow research applications (Kirk et al., 2005; Tremblay et al., 2018; De Koster et al., 2019). Of these, K-means is an effective partition-based clustering algorithm, which has been widely used in the literature. However, it is apparent that our understanding of this type of variability in dairy calves is limited, and research in this area is needed.

Previous results showed that dietary butyrate supplementation can stimulate the gastrointestinal tract development in dairy calves (Guilloteau et al., 2009; Górka et al., 2011a,b). However, the combination of ad libitum MR feeding and butyrate supplementation did not show a synergistic effect on postnatal growth or anabolic processes in dairy calves (Frieten et al., 2017, 2018). Recently, Koch et al. (2019) indicated an elevated growth of the small intestinal mucosa and no negative effect on rumen development at weaning due to ad libitum MR feeding and butyrate supplementation.

Therefore, the objectives of our study were to (1) apply statistical and K-means clustering approach to classify ad libitum-fed calves according to their MR meal size (MR intake per rewarded visit) into subgroups (clusters), (2) investigate the effects of MR meal size on feed intake, growth performance, blood metabolites, and hormones related to nutrient intake and growth (e.g., glucose, triglycerides, BHB, IGF-I, insulin) of ad libitum MR-fed calves in different subgroups, and (3) assess whether MR meal size, calf performance, blood metabolites, and hormones were affected by the butyrate supplementation in different subgroups. We hypothesized that (1) distinct clustering patterns exist with regards to the feeding behavior of dairy calves when considering longitudinal data from ad libitum MR-fed calves with regards to patterns of MR meal size, and (2) calves in different clusters (with regard to MR meal size) would differ in growth performance, and butyrate supplementation would not affect the clustering by meal size.

\section{MATERIALS AND METHODS}

The animal experiment was conducted at the Educational and Research Centre for Animal Husbandry (Hofgut Neumuehle, Germany). All experimental procedures were reviewed and approved (registration no. $23177-07 /$ G 13-20-069) by the relevant Department for Animal Welfare Affairs (Landesuntersuchungsamt Rheinland-Pfalz, Koblenz, Germany), following the 
German Animal Welfare Act (Federal Republic of Germany, 2014).

\section{Calves, Management, and Diets}

The current study is part of recently published companion studies (Frieten et al., 2017; 2018; Gerbert et al., 2018), which report the growth performance, blood metabolic and endocrine measurements, and feeding behavior in dairy calves that received MR $[125 \mathrm{~g}$ of powder/L of MR; $21.7 \% \mathrm{CP}, 18.6 \%$ fat, $0.2 \%$ crude fiber; $18.34 \% \mathrm{ME}(\mathrm{MJ} / \mathrm{kg}$ of $\mathrm{DM})$; Trouw Nutrition Deutschland GmbH, Burgheim, Germany] either ad libitum (up to $25 \mathrm{~L} / \mathrm{d}$ ) or restrictively $(6 \mathrm{~L} / \mathrm{d}$ ) by automatic MR feeder (Förster-Technik GmbH, Engen, Germany) as described below. In the current study, we performed a cluster analysis only on ad libitum MRfed calves. A total of 32 German Holstein calves (16 males and 16 females, birth weight between 37 and 53 $\mathrm{kg}$, born between June 2014 and February 2015) with free access to MR (maximum $25 \mathrm{~L} / \mathrm{d}$ ) were studied from birth until d 77 of age. Only healthy calves with complication-free births were used in the trial.

All calves received $2.5 \pm 0.09 \mathrm{~kg}$ (mean $\pm \mathrm{SD}$ ) of colostrum from their dams within $2 \mathrm{~h}$ after birth with a calf feeder (Speedy Feeder, Shoof International Ltd., Cambridge, New Zealand). Calves (2-3 h after birth) were moved into single calf hutches bedded with straw for the first $10 \pm 3$ (mean $\pm \mathrm{SD}$ ) d of age. Calves received acidified transition milk ad libitum from their dams (2 mL of acidifier/L of milk; H. W. Schaumann GmbH, Pinneberg, Germany) for the next 5 meals (2.5 d). From meal 7 (d 4) onwards, calves were fed MR (125 $\mathrm{g}$ of powder/L of MR) ad libitum (up to $25 \mathrm{~L} / \mathrm{d}$ ). Half of the calves received MR with butyrate supplementation $(0.33 \%$ calcium-sodium butyrate of DM; Benelux GmbH, Amel, Belgium).

Calves were fed MR via bucket twice daily with an artificial teat in hutches, and if necessary, the buckets were reloaded to ensure that buckets were never without MR. After the first period in the hutches $(10 \pm 3 \mathrm{~d})$, calves were moved into an open stable. The stable was divided into 2 identical pens (for calves fed MR either with or without butyrate, respectively), each with a $30.5-\mathrm{m}^{2}$ straw-bedded lying area. A maximum number of 15 calves per pen were housed at once. For each pen, 1 automatic MR feeder (Förster-Technik GmbH) was available, respectively. Each MR feeder had 2 drinking stations, 1 drinking station for calves younger than 3 wk (maximum; $\mathrm{n}=3$ ) of age and 1 drinking station for calves $4 \mathrm{wk}$ of age and older, to ensure that young calves had sufficient access to the MR feeding station (Gerbert et al., 2018). From time to time, young calves from the hutches needed to be trained at the automatic feeders. One concentrate feeder for each pen was available for individual concentrate feeding. The maximum intake of $\mathrm{MR}$ as a fixed setting from the automatic feeder was $25 \mathrm{~L} / \mathrm{d}$ of MR until d 56 of age, and individual portions per day were limited to $5.5 \mathrm{~L} /$ meal, followed by an off time of $30 \mathrm{~min}$ after the end of the meal. The lower limit of MR intake was set by 1.5 L. Calf feeders were calibrated continuously during this study once a week. Furthermore, the automatic MR feeder had an automatic calibration and showed an alarm if incorrect. The MR was stepped down linearly over $13 \mathrm{~d}$ at d 57 of age from $25 \mathrm{~L}$ to $2 \mathrm{~L}$ of MR per day $(1.9 \mathrm{~L}$ of $\mathrm{MR} / \mathrm{d})$ until $\mathrm{d} 70$ of age in all groups. Thereafter, all calves received $2 \mathrm{~L} / \mathrm{d}$ of $\mathrm{MR}$ until the end of the experiment on d 77 of calf age. More details about milk feeding via automatic MR feeder and health management were provided in the previous publication (Gerbert et al., 2018). Ingredients and nutrient composition of MR and concentrate (provided as pellets; Raiffeisen Waren-Zentrale Rhein-Main eG, Köln, Germany) are given in Table 1.

Table 1. Nutrient and chemical composition of the milk replacer and concentrate

\begin{tabular}{lcc}
\hline $\begin{array}{l}\text { Item, \% of DM unless } \\
\text { noted otherwise }\end{array}$ & Milk replacer $^{1}$ & Concentrate $^{2}$ \\
\hline $\mathrm{DM}, \mathrm{g} / \mathrm{kg}$ & 968 & 866 \\
$\mathrm{CP}$ & 21.7 & 21.0 \\
Crude fat & 18.6 & 4.2 \\
Crude fiber & 0.2 & 5.9 \\
$\mathrm{ADFOM}^{3}$ & $\mathrm{ND}$ & 8.1 \\
$\mathrm{NDFOM}^{3}$ & $\mathrm{ND}$ & 16.5 \\
Ash $^{\text {NFE }}$ & 7.3 & 7.0 \\
Total sugar & 52.1 & 61.9 \\
ME ${ }^{5}$ MJ/kg of DM & 44.9 & $\mathrm{ND}$ \\
Ca & 18.34 & 13.15 \\
$\mathrm{P}$ & 1.17 & 1.22 \\
Na & 0.65 & 0.66 \\
$\mathrm{~K}$ & 0.47 & 0.29 \\
Lysine & 1.43 & 1.21 \\
Methionine & 1.8 & $\mathrm{ND}$ \\
& 0.48 & $\mathrm{ND}$
\end{tabular}

${ }^{1}$ Ingredients of milk replacer: $50 \%$ skim milk powder, $25 \%$ whey powder, $16.5 \%$ vegetable oil, $3 \%$ wheat powder; milk replacer fed to calves with different milk replacer meal size as high (HI) or low (LO) per rewarded visit supplemented without (HIB-; LOB-) or with $0.33 \%$ calcium-sodium butyrate ( $\mathrm{HIB}+$; $\mathrm{LOB}+$ ). $\mathrm{ND}=$ not determined.

${ }^{2}$ Ingredients: $35.0 \%$ corn, $23.0 \%$ soybean meal, $13.0 \%$ beet pulp dried with molasses, $7.5 \%$ wheat, $6.0 \%$ barley, $3.2 \%$ rapeseed meal, $3.0 \%$ linseed meal, $3.0 \%$ beet pulp, $2.0 \%$ wheat bran, $0.09 \%$ calcium carbonate, and $0.05 \%$ monocalcium phosphate.

${ }^{3}$ Acid detergent fiber and NDF are expressed exclusive of residual ash. The NDF was assayed with a heat-stable amylase (Korst et al., 2017). ${ }^{4}$ Nitrogen-free extract, calculated as NFE $=100-(\mathrm{CP}+$ crude fat + crude fiber + ash).

${ }^{5} \mathrm{ME}$ calculated using the following equation: $\mathrm{ME}, \mathrm{MJ} / \mathrm{kg}$ of $\mathrm{DM}=$ $(24.2 \times \mathrm{CP}+36.6 \times$ fat $+17.0 \times$ total sugar $) / 100 \times 0.97 \times 0.96$. 
Health exams including rectal temperature, fecal score $(1=$ well-formed; $2=$ pasty, but formed; $3=$ smooth; and $4=$ watery $)$, navel score $(1=$ normal; 2 = edematous; $3=$ inflammatory), and respiratory tract $(1=$ healthy; $2=$ runny nose; $3=$ heavy breathing, cough) were conducted daily based on the University of Wisconsin-Madison Calf Health Scoring system (School of Veterinary Medicine, 2017).

\section{Data Recording, Sampling, and Laboratory Analyses}

The intakes of milk and MR in the hutches were recorded daily by weighing residues with an electronic scale (Sartorius AG, Göttingen, Germany). After moving to the barn, feed intake and feeding behavior data were recorded by the automatic MR feeder. The number of rewarded visits (per d), unrewarded visits (per d), amount of MR intake per meal (L/meal) and day $(\mathrm{L} / \mathrm{d})$, drinking speed per meal $(\mathrm{mL} / \mathrm{min})$, and total visits (per d) of each calf were provided by the PCprogram Kalb Manager WIN (Förster-Technik GmbH). The original data concerning feed intake and feeding behavior were published by Gerbert et al. (2018). The calf's birth BW was recorded using a mobile scale (TruTest Ltd., Auckland, New Zealand) after the first colostrum intake. To obtain an accurate measurement of the BW at birth, the exact amount of ingested colostrum was subtracted from the initial weight. Calf BW was recorded weekly, and the ADG was calculated based on the difference in $\mathrm{BW}$ with the precise number of days between weighing.

The nutrient compositions of the concentrate and MR were analyzed using an accredited external laboratory (Landwirtschaftliche Untersuchungs-und Forschungsanstalt, Speyer, Germany) according to the Weender standard procedure (Naumann and Bassler, 2004). The analyses of feedstuff were used to determine the ME content of concentrate (Gesellschaft für Ernährungsphysiologie, 2009). The composition of energy and DM from individual colostrum milkings was calculated by the measurements from Kühne et al. (2000). Gross energy for colostrum and MR was transformed into $\mathrm{ME}$ as follows: $\mathrm{ME}=0.97 \times 0.96$ $\times$ gross energy (NRC, 2001). The MR energy content was calculated as gross energy on energy equivalents of $36.6,24.2$, and $17.0 \mathrm{MJ} / \mathrm{kg}$ of DM for crude fat, CP, and total sugar, respectively.

Blood samples were collected by jugular venipuncture before first colostrum intake (d 1), $24 \mathrm{~h}$ after colostrum feeding (d 2), before first MR feeding (d 4), and subsequently on d $7,14,21,28,35,42,49,56,63,70$, and 77 (Frieten et al., 2017). Before colostrum feeding, 50 $\mathrm{mL}$ of the first colostrum from each dam was stored at $-20^{\circ} \mathrm{C}$ in single tubes (Cellstar centrifuge tubes, Greiner Bio-One GmbH, Frickenhausen, Germany). Colostrum quality was determined by 2 different digital refractometers (Wine refractometer, HI96811, Hanna instruments Inc., Woonsocket, RI; Pocket Refraktometer, Atago USA Inc., Bellevue, WA), and IgG1, IgG2, and IgM concentrations were determined as described previously by Gerbert et al. (2018).

Blood samples were stored in an ice-water bath before centrifugation $(3,500 \times g$ for $10 \mathrm{~min}$ at room temperature). The plasma samples were immediately aliquoted and stored in a $-20^{\circ} \mathrm{C}$ freezer until analyzed. Plasma concentrations of $\gamma$-glutamyl transferase (GGT), albumin, glucose, urea, nonesterified fatty acid (NEFA), BHB, total protein (TP), cholesterol, triglyceride, lactate, and total bilirubin were analyzed in tubes that contained sodium fluoride $(2-4 \mathrm{mg} / \mathrm{mL})$ and potassium oxalate $(1-3 \mathrm{mg} / \mathrm{mL})$. The plasma concentrations of $\operatorname{IgG} 1, \operatorname{IgG} 2$, and $\operatorname{IgM}$ (d 1, 4, 14, 28, 42, 56, and 77), fibrinogen, and serum amyloid A (SAA; d 1, 4, 7, 21, 35, 49, 63, and 77) were analyzed in tubes containing potassium-EDTA (1.8 mg/ $\mathrm{mL})$. All blood metabolites were analyzed using the spectrophotometric method (ABX Pentra 400, Horiba ABX, Montpellier, France) and the following kits: albumin (\#A11A01664) and GGT (\#A11A01630) from Horiba ABX; glucose (\#A11A01667), lactate (\#A11A01721), and triglyceride (\#A11A01640) from Axon Lab AG, Baden, Switzerland; BHB (\#RB1008), urea (\#LT-UR 0010), and total bilirubin (\#LT-BR 0500) from LABOR + TECHNIK Eberhard Lehmann GmbH, Berlin, Germany; NEFA (\#434-91795) from Wako Chemicals GmbH, Neuss, Germany; TP (\# 553-412) and cholesterol (\#553-127) from mti diagnostics GmbH, Idstein, Germany, were analyzed as described previously (Frieten et al., 2017; Gerbert et al., 2018). Plasma immunoglobulin concentrations were measured by ELISA as described previously by Gruse et al. (2016). Plasma fibrinogen concentration was analyzed by rapid heat precipitation as described previously (Millar et al., 1971). Plasma SAA concentration was analyzed using a multispecies ELISA kit (no. TP-802) as described previously by Gerbert et al. (2018).

The measurement of endocrine traits was first published by Frieten et al. (2017, 2018). The plasma IGF-I concentration was analyzed by ELISA (Frieten et al., 2018). The plasma IGF binding proteins IGFBP2, IGFBP3, and IGFBP4 were measured by quantitative Western Ligand Blot analysis as previously described (Schäff et al., 2016; Frieten et al., 2018). Plasma concentrations of glucagon (catalog no. RIA-1258) and insulin (catalog no. RIA-1257) were analyzed by ra- 
dioimmunoassay using kits (DRG Instruments GmbH, Marburg, Germany) adapted to bovine subjects (Hammon et al., 2009). The plasma cortisol concentration was analyzed using an ELISA kit (catalog no. EIA1887; Gruse et al., 2016), which was validated for the use of bovine plasma.

\section{Clustering and Statistical Analyses}

The K-means cluster procedure of the SAS package (PROC FASTCLUS; SAS Institute Inc., Cary, NC) was applied on a daily MR meal size record of dairy calves to generate clusters. The mean, sum, and standard deviation of MR meal size during the entire study were included as main features for the clustering process to classify the calves into subgroups. For clustering validation, the estimation of the optimal number of clusters for K-means clustering was done by the direct method in R (version 4.0.3; R Core Team, 2019), which consisted of optimizing a criterion (the within-cluster sums of squares or the average silhouette) using the elbow (Supplemental Figure S1A, https://dx.doi.org/ 10.22000/361) and average silhouette (Rousseeuw, 1987; Supplemental Figure S1B) methods, respectively. Here, we defined the statistical power as the probability of cluster analysis to reject the null hypothesis (no clustering can be found), which was characterized by an average silhouette width above 0.5 (Kaufman and Rousseeuw, 1990). According to the results, the optimal number of clusters was 3 . The K-means cluster analysis on the MR meal size data collected from the automatic feeder resulted in 3 clusters $(\mathrm{n}=14, \mathrm{n}=12$, and $\mathrm{n}$ $=6$ ). In both clusters, butyrate supplementation was equally distributed and failed to affect a difference in MR meal size. Two clusters with a sufficient cluster size $(n=14$ and $n=12)$ were included for further statistical analysis using repeated measures mixed-model ANOVA. Cluster 1 showed calves with higher MR meal size $(\mathbf{H I} ; 2.2 \pm 0.11 \mathrm{~L} /$ visit $\mathrm{MR} ; \mathrm{n}=12)$, and cluster 2 showed calves with lower meal size $(\mathbf{L O} ; 1.8 \pm 0.07 \mathrm{~L} /$ visit $M R ; n=14)$, that were supplemented $M R$ without $(\mathbf{H I B}-, \mathrm{n}=6$; LOB,$- \mathrm{n}=7)$ or with $0.33 \%$ calciumsodium butyrate $(\mathbf{H I B}+, \mathrm{n}=6$; $\mathbf{L O B}+, \mathrm{n}=7)$.

Descriptive statistics were performed on MR meal size, MR intake, total DM intake, total ME, concentrate DM intake, BW, ADG, gain-to-feed ratio, total visits, unrewarded visits, rewarded visits, and drinking speed using SigmaStat (V2.03, SPSS Inc., Chicago, IL). Power analysis for sample size estimation was performed (Morris, 1999; Hintze, 2008) for the primary response variables, including feed intake, BW, and ADG based on previously published values (DeVries and von Keyserlingk, 2009; Zhang et al., 2010; Miller-Cushon and DeVries, 2011). From the power test analysis, using $\alpha=0.05$ and power $=0.80$, the projected sample size was 12 calves per treatment for starter intake, DMI, $\mathrm{ADG}$, and BW.

We analyzed the data from the clusters (HIB-, HIB +, $\mathrm{LOB}-$, and $\mathrm{LOB}+$ ) in SAS using PROC MIXED with repeated measures for time point comparison. Butyrate was included in the model because half of the calves received MR with $0.33 \%$ calcium-sodium butyrate. The model consisted of sex (levels: male, female), treatment (levels: HI, LO), butyrate supplementation (level: yes, no), time (levels: d 1, 2, 7, 14, 21, 28, 35, 42, 49, 56, 63,70 , and 77 after birth), and respective interactions as fixed effects, and calves as a random effect. A compound symmetry covariance structure was chosen based on the best fit to the data. All the data (performance data; metabolic, inflammatory, and endocrine measurements in blood plasma; data on feeding behavior) were screened for normality of distribution using the UNIVARIATE procedure of SAS (the Shapiro-Wilk test) before analysis. Among all variables, the rewarded visits, drinking speed, concentrate intake, and ME intake were normally distributed, but the rest of the values were not normally distributed. The parameter that was not normally distributed was transformed using a $\log _{10}$ transformation. Initial BW was considered as a covariate for the final BW. Additionally, group differences in these least squares means (LSM) were tested using the Tukey-Kramer procedure. The SLICE statement of the MIXED procedure (PROC MIXED) of SAS was used to conduct partitioned analyses of the LSM for interactions. Outliers were identified as values with standard deviations (SD) $>2$ by Z-standardization and excluded. Data were reported as LSM and were tested using ANOVA. Significance was declared at $P \leq 0.05$, and the trend threshold was set at $0.05<P \leq 0.10$.

\section{RESULTS}

\section{Descriptive Statistics}

The descriptive statistics for MR meal size, MR intake, total DM intake, total $\mathrm{ME}$, concentrate DM intake, total visits, unrewarded visits, rewarded visits, drinking speed, BW, ADG, and gain-to-feed ratio are shown in Table 2. We found a large range (between 0.46 and $5.56 \mathrm{~L}$ per rewarded visit) in MR meal size when calves fed ad libitum MR. The ad libitum MR-fed calves in the present study also showed a large range $(19.80 \mathrm{~L} / \mathrm{d})$ in the MR intake between 0.99 and 20.79 $\mathrm{L} / \mathrm{d}$ during the preweaning period. We observed a large variation in feeding behaviors such as total visits (range $=39.70$ per $\mathrm{d}$ ), unrewarded visits (range $=35.40$ per 
Table 2. Descriptive statistics for milk replacer (MR) meal size, MR intake, total DMI, total ME, concentrate DMI, total visits, unrewarded visits, rewarded visits, drinking speed, BW, ADG, and gain-to-feed ratio in ad libitum-fed calves [across 2 clusters with a sufficient cluster size ( $\mathrm{n}=14$ and $\mathrm{n}=12)$ ]

\begin{tabular}{|c|c|c|c|c|c|c|}
\hline Item & Mean & Minimum & Maximum & $\mathrm{SD}$ & Range & $\mathrm{CV}$ \\
\hline MR intake, L/d & 10.40 & 0.99 & 20.79 & 4.02 & 19.80 & 0.39 \\
\hline Total ME intake, MJ/d & 25.87 & 9.86 & 44.86 & 6.34 & 35.0 & 0.24 \\
\hline Concentrate DMI, kg/d & 0.35 & 0.00 & 3.25 & 0.61 & 3.25 & 1.73 \\
\hline Total visits, number of visits per day & 8.01 & 2.20 & 41.90 & 5.52 & 39.70 & 0.69 \\
\hline Drinking speed, $\mathrm{mL} / \mathrm{min}$ & 565.4 & 192.6 & 906.6 & 140.3 & 714.0 & 0.25 \\
\hline $\mathrm{BW}, \mathrm{kg}$ & 80.29 & 37.0 & 140.3 & 24.62 & 103.3 & 0.31 \\
\hline $\mathrm{ADG}, \mathrm{g} / \mathrm{d}$ & 971.3 & -825 & 2,143 & 458 & 2,968 & 0.47 \\
\hline Gain-to-feed ratio & 0.64 & -0.97 & 1.92 & 0.34 & 2.89 & 0.53 \\
\hline
\end{tabular}

d), rewarded visits (range $=714.0$ per d), and drinking speed (range $=714.0 \mathrm{~mL} / \mathrm{min}$ ). We also found large variation in ADG (range $=2,968 \mathrm{~g} / \mathrm{d}$ ) among calves with free access to MR.

The descriptive statistics including SD, interquartile range, first quartile, and third quartile as well as $95 \%$ confidence intervals for these parameters in ad libitum-fed calves for 2 clusters with a sufficient cluster size $(\mathrm{LO} \mathrm{n}=14$; and $\mathrm{HI} \mathrm{n}=12)$ are presented in Supplemental Table S1 (https://dx.doi.org/10.22000/ 361). On average, HI calves drank 2.17 L per rewarded visit, whereas LO calves drank approximately $1.80 \mathrm{~L}$ per rewarded visit with no differences in the number of rewarded and unrewarded visits as well as the total visits. The $\mathrm{SD}$ of the MR intake (L/d) was 6.09 and 6.39 for the HI and LO groups, respectively. We found a large SD in drinking speed (141 and 133) for the HI and LO groups, respectively. However, low SD was observed for the total visits (5.85 and 5.48), rewarded visits (1.81 and 2.11), and unrewarded visits (5.95 and 5.90) in the $\mathrm{HI}$ and LO groups, respectively.

\section{Clustering Results}

Calves were clustered into 2 groups according to their meal size (MR intake per rewarded visit) as HI (2.2 \pm $0.11 \mathrm{~L}$ of MR per visit; $\mathrm{n}=12 ; 7$ males, 5 female) or LO $(1.8 \pm 0.07 \mathrm{~L}$ of MR per visit; $\mathrm{n}=14 ; 4$ males, 10 females; Table 3). Figure 1A indicates the MR meal size of calves fed MR ad libitum at the automatic MR feeder system with a HI and LO MR meal size per rewarded visit during the experimental period. The MR meal size increased over time between wk 3 and 9 for HI calves, but was held constant for LO calves. In both clusters, butyrate supplementation was equally distributed and failed to affect a difference in MR meal size.

\section{Intake, Growth Performance, and Feeding Behavior}

Data for feed intake, growth performance, and feeding frequency patterns are presented in Table 3. Intakes of MR (Figure 1B), ME, DM, CP, and crude fat via $\mathrm{MR}$ did not differ between $\mathrm{HI}$ and $\mathrm{LO}$ calves. Intakes of DM (concentrate, 0.36 vs. $0.26 \pm 0.03 \mathrm{~kg} / \mathrm{d}, \mathrm{LSM} \pm$ SEM ; $P=0.08$; Figure 2$), \mathrm{ME}(4.63$ vs. $3.35 \pm 0.43$ $\mathrm{MJ} / \mathrm{d} ; P=0.08), \mathrm{CP}(73.9$ vs. $53.5 \pm 6.95 \mathrm{~g} / \mathrm{d} ; P=$ $0.08)$, and crude fat (14.8 vs. $10.7 \pm 1.39 \mathrm{~g} / \mathrm{d} ; P=0.08)$ via concentrate as well as total intakes of DM (1.63 vs. $1.48 \pm 0.03 \mathrm{~kg} / \mathrm{d} ; P=0.10), \mathrm{ME}(27.1$ vs. $24.7 \pm 0.38$ $\mathrm{MJ} / \mathrm{d} ; P=0.09)$, and CP $(352$ vs. $318 \pm 5.22 \mathrm{~g} / \mathrm{d} ; P=$ $0.10)$ tended to be greater $(P=0.08)$ in HI than in LO. The concentrate intakes showed a more distinct difference between $\mathrm{HI}$ than $\mathrm{LO}$ at the end of the study ( $P$ $<0.01)$. The average BW did not differ among groups, but it tended $(P=0.08)$ to be lower in butyrate-fed groups and was numerically lower for the LOB + calves than other calves. The ADG was greater $(P=0.04)$ in $\mathrm{HI}$ than in LO and was reduced by butyrate feeding $(P$ $=0.05)$. Gain-to-feed ratio and ADG divided by ME did not differ among groups.

The number of rewarded (Figure 3A) and unrewarded (Figure 3B), and total visits (Figure 3C) per day did not differ among groups, but the drinking speed per meal (Figure 3D) for each calf was higher $(P<0.01)$ in HI than LO (606 vs. $533 \pm 8.73 \mathrm{~mL} / \mathrm{min}, \mathrm{LSM} \pm$ SEM). The drinking speed per meal for each calf $(P<$ 0.01) was greater in MR-fed calves without butyrate than with butyrate ( 623 vs. $516 \pm 8.73 \mathrm{~mL} / \mathrm{min})$.

\section{Measurements in Blood}

Data for blood metabolites and hormones are presented in Table 4. Blood plasma concentrations of GGT, 
Table 3. Intakes of DM, ME, CP, and fat of liquid, concentrate, and total feed [milk replacer (MR) and concentrate], MR meal size, as well as feeding behavior, BW, ADG and gain-to-feed ratio in calves, fed ad libitum milk replacer (MR) as high (HI) or low (LO) per rewarded visit supplemented MR without (HIB-; LOB-) or with $0.33 \%$ calcium-sodium butyrate (HIB+; LOB +) during the first 11 wk of age

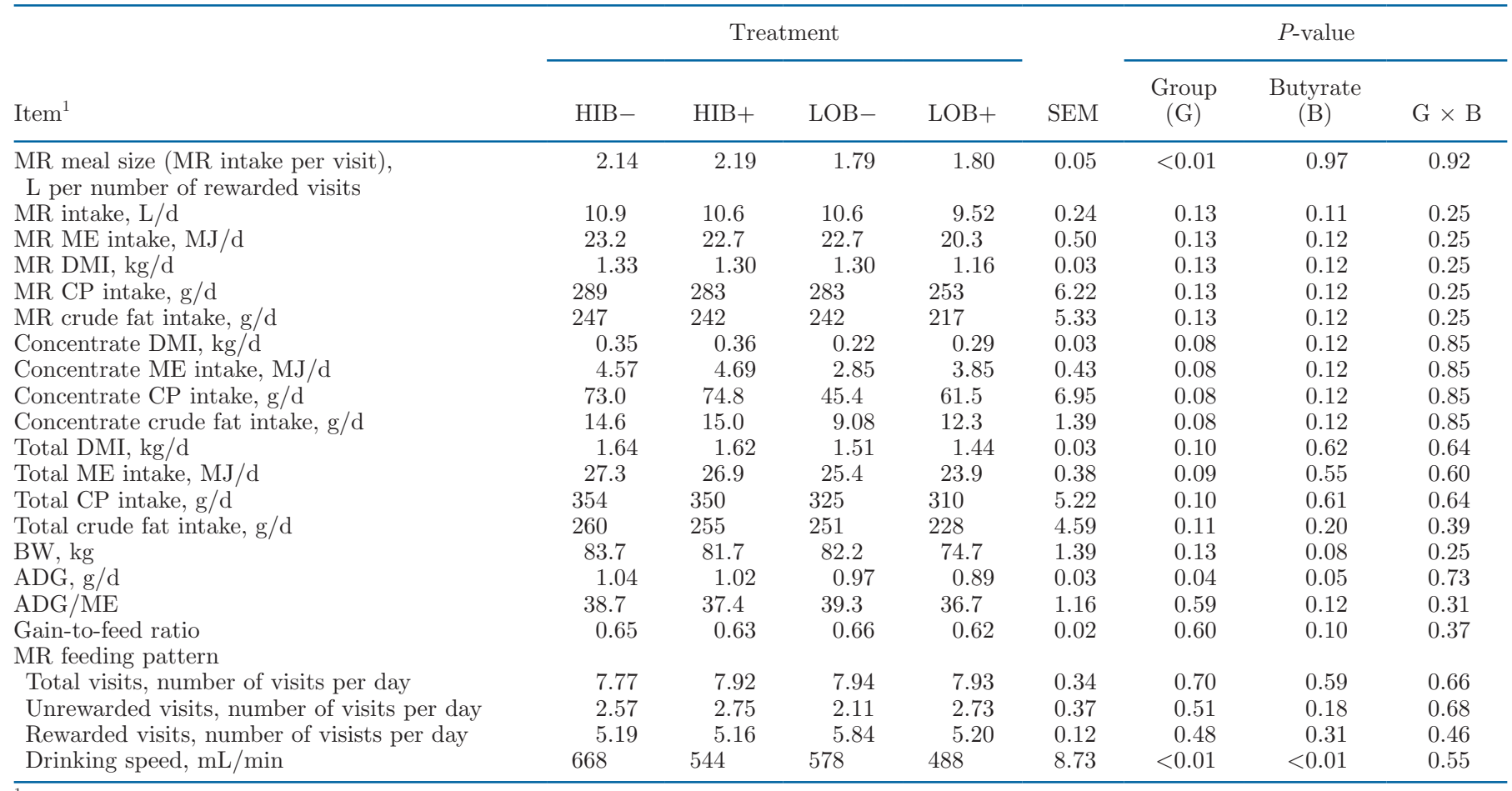

${ }^{1}$ Values are presented as LSM.

lactate, triglycerides, total bilirubin, NEFA, IGFBP2, IGFBP4, IGFBP3/2, IgG1, IgG2, IgM, and fibrinogen did not differ between $\mathrm{HI}$ and LO calves. Plasma concentrations of glucose $(6.12$ vs. $5.82 \pm 0.07 \mathrm{mmol} / \mathrm{L}$, $\mathrm{LSM} \pm \mathrm{SEM} ; P=0.04$; Figure $4 \mathrm{~A})$, insulin (0.99 vs. $0.77 \pm 0.06 \mu \mathrm{g} / \mathrm{L} ; P=0.01 ;$ Figure $4 \mathrm{~B})$, glucagon $(158$ vs. $129 \pm 3.61 \mathrm{ng} / \mathrm{L} ; P<0.01$; Figure 4C), IGF-I (269 vs. $245 \pm 0.07 \mu \mathrm{g} / \mathrm{L}$; tendency $P=0.07$; Figure $4 \mathrm{D})$, albumin (25.8 vs. $25.0 \pm 0.11 \mathrm{~g} / \mathrm{L} ; P=0.02$; Figure $4 \mathrm{E}), \mathrm{TP}(54.2$ vs. $51.6 \pm 0.3 \mathrm{~g} / \mathrm{L} ; P<0.01$; Figure $4 \mathrm{~F}$ ), and $\mathrm{BHB}(0.063$ vs. $0.060 \pm 0.003 \mathrm{mmol} / \mathrm{L} ; P=$ 0.04; Figure $4 \mathrm{~F}$ ) were higher in HI than in LO. Plasma concentrations of SAA $(81.0$ vs. $77.4 \pm 5.01 \mathrm{mg} / \mathrm{L} ; P=$ $0.07)$ tended to be greater in HI than in LO.

Blood plasma concentrations of lactate (1.18 vs. 1.02 $\pm 0.7 \mathrm{mmol} / \mathrm{L} ; P=0.02$ ), total bilirubin (4.04 vs. 3.51 $\pm 0.18 \mu \mathrm{mol} / \mathrm{L} ; P=0.01$ ), and $\operatorname{IgM}(0.77$ vs. $0.66 \pm$ $0.18 \mathrm{~g} / \mathrm{L} ; P=0.05)$ were greater, but IGF-I (244 vs. $271 \pm 4.08 \mu \mathrm{g} / \mathrm{L} ; P=0.02)$ and IGFBP3:IGFBP2 ratio (2.43 vs. $2.94 \pm 0.14 ; P<0.01)$ were lower in calves fed MR with butyrate than without butyrate.

An interaction was found between the MR meal size and butyrate supplementation regarding effects on the plasma concentrations of cholesterol $(P<0.01)$, urea $(P=0.01)$, cortisol $(P<0.05)$, and IGFBP3 (tendency,
$P=0.07)$. The lowest values were observed for plasma concentrations of urea $(2.18 \mathrm{mmol} / \mathrm{L})$ and cortisol $(12.2$ $\mu \mathrm{g} / \mathrm{L}$ ) in LOB - and for plasma cholesterol in HIB+ calves. Plasma IGFBP3 concentrations were highest in $\mathrm{HIB}+$ calves $(1,556 \mu \mathrm{g} / \mathrm{L})$.

\section{DISCUSSION}

High interindividual variability in the feeding behavior of dairy calves makes it difficult to assess their growth performance and welfare objectively and, consequently, to generalize results across studies. Feeding calves milk or MR ad libitum with computerized automatic feeders allows the calf to express natural behaviors in terms of the frequency, size, and duration of meals (Appleby et al., 2001; Jensen and Holm, 2003; Borderas et al., 2009). In the current study, calves consumed large amounts of MR up to $20.79 \mathrm{~L} / \mathrm{d}$ with an average consumption of $10.4 \mathrm{~L} / \mathrm{d}$ until wk 11, which is in line with an earlier study (de Passillé et al., 2008), but the number of meals was less than observed by Appleby et al. (2001) and O'Driscoll et al. (2006). Appleby et al. (2001) reported that calves with ad libitum access to milk from artificial teats consumed about 10 meals/d. Also, O'Driscoll et al. (2006) reported that ad libitum 
A

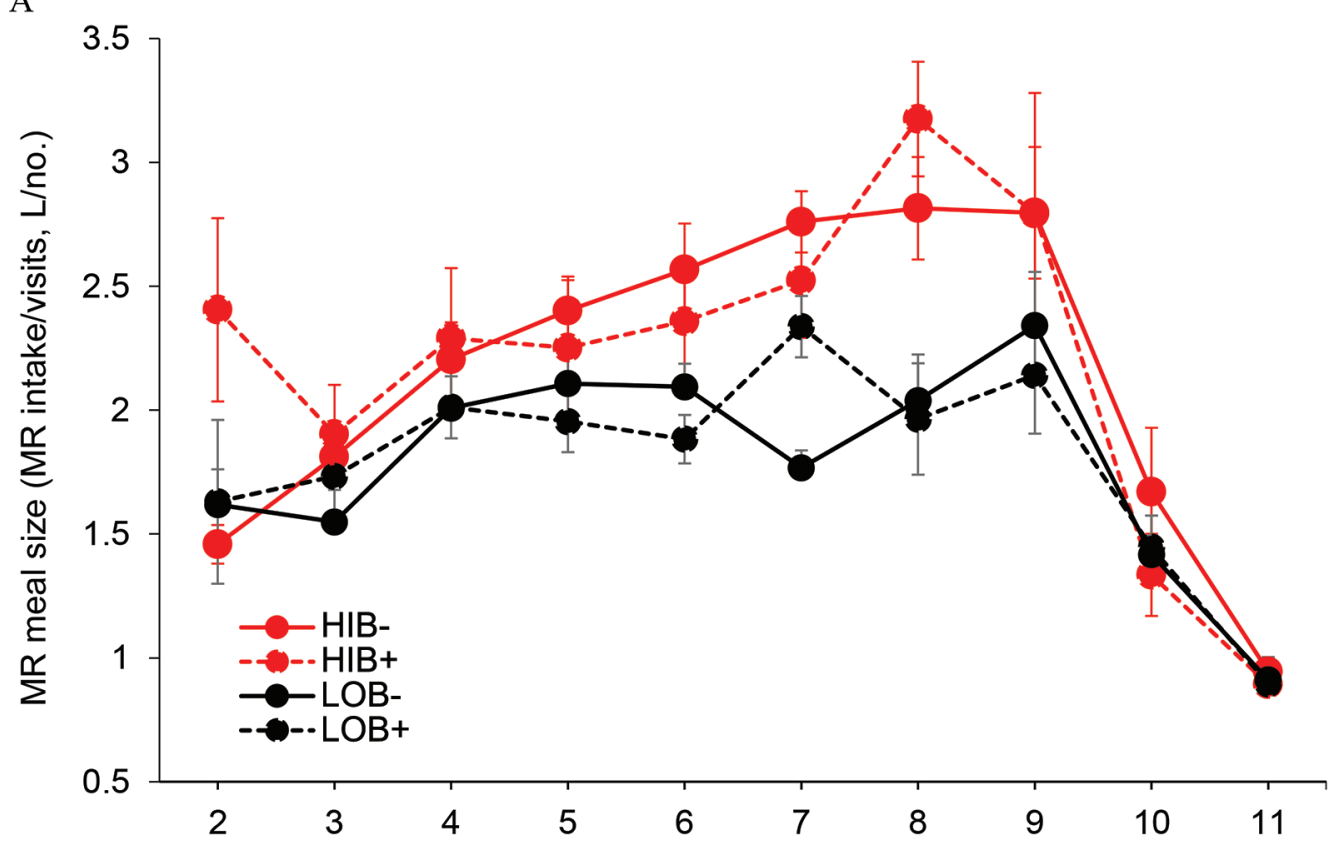

B

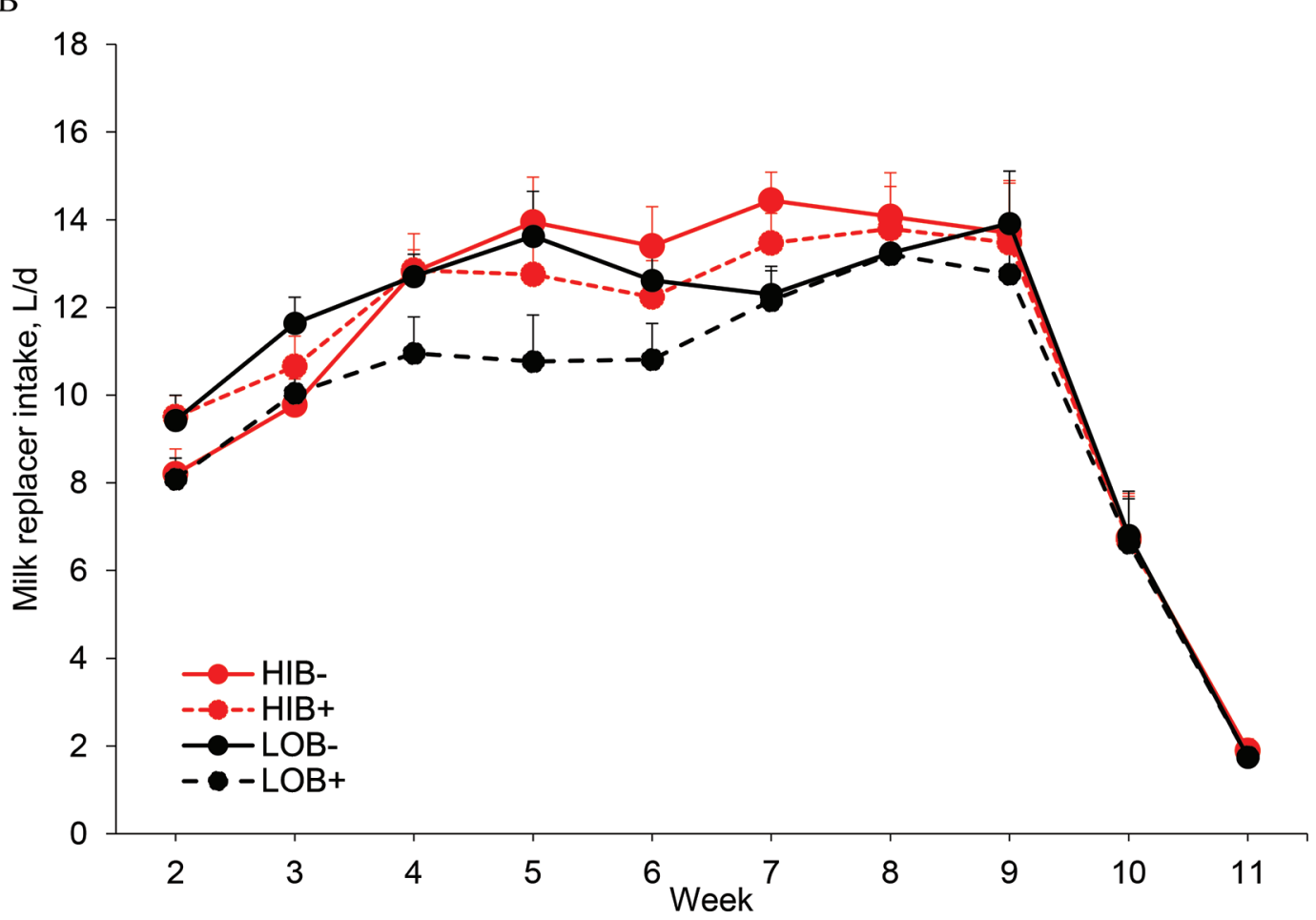

Figure 1. Milk replacer (MR) intake per rewarded visit (A) and MR intake per day (B) of calves fed ad libitum milk replacer (MR) with high (HI) and low (LO) MR meal size supplemented MR without (HIB-, LOB-) or with $0.33 \%$ calcium-sodium butyrate (HIB+, LOB+). Data are presented as means $\pm \mathrm{SE}$.

calves fed approximately $12 \mathrm{~L}$ of milk distributed into 10 meals from a computerized automatic milk feeder. Whereby, the latter studies fed whole milk, which differed from the automatic MR feeding in our study. To some degree, meal patterns of calves are highly subjective to the level of milk feeding (Hammon et al., 2002; Jensen and Holm, 2003; Miller-Cushon et al., 2013) and also depend on housing, the competition to milk access 


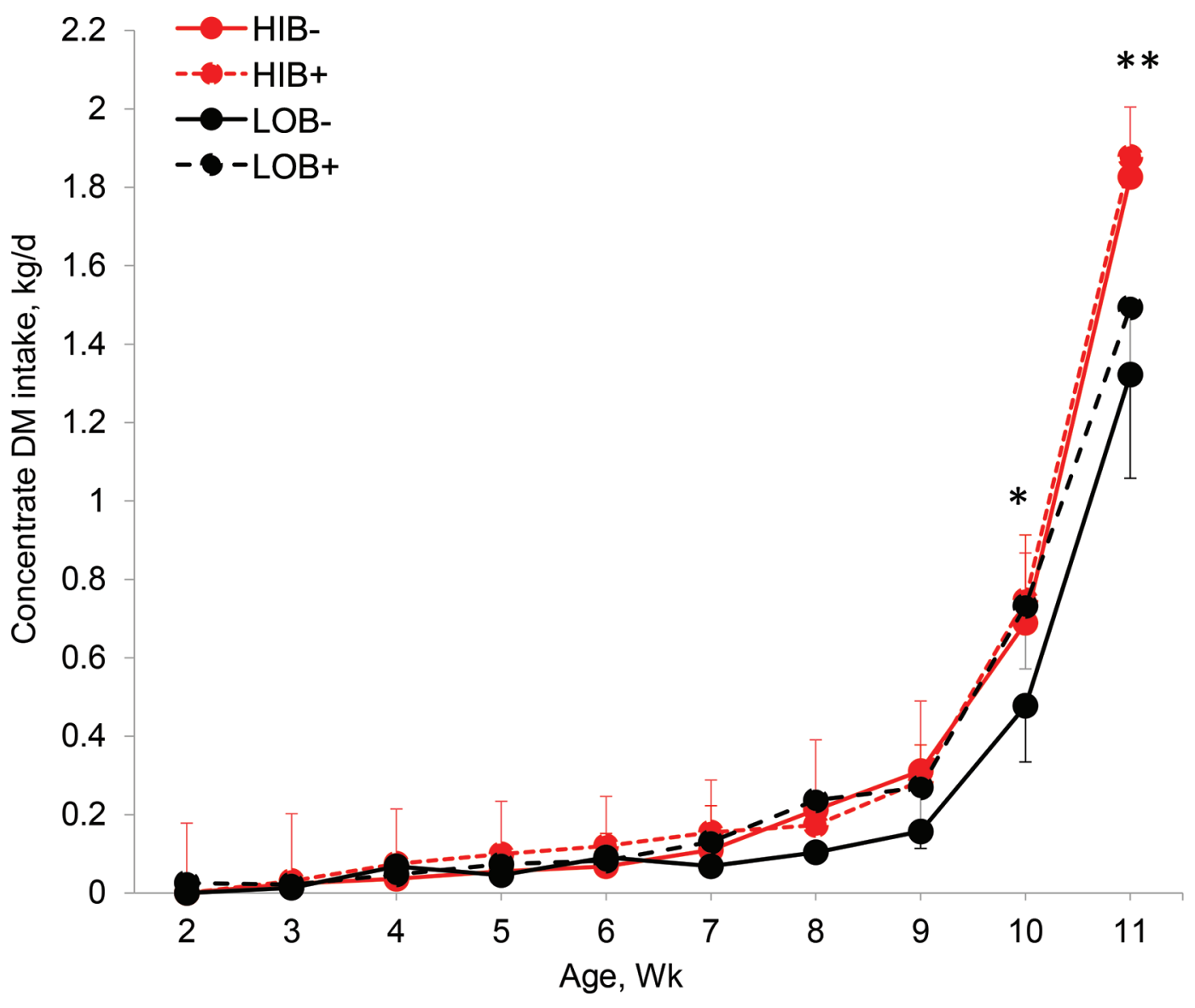

Figure 2. Concentrate intake of calves fed ad libitum milk replacer (MR) with high (HI) and low (LO) MR meal size supplemented MR without $(\mathrm{HIB}-, \mathrm{LOB}-)$ or with $0.33 \%$ calcium-sodium butyrate $(\mathrm{HIB}+, \mathrm{LOB}+)$. Data are presented as means $\pm \mathrm{SE} .{ }^{*}$ Indicates a difference $\left({ }^{*} P<0.05 ;{ }^{*} P<0.01\right)$ between the groups at a given time.

within the group, and group size (Jensen, 2004; Jensen and Budde, 2006; Miller-Cushon and DeVries, 2015).

Meal patterns are controlled by satiety mechanisms (Guilloteau et al., 1997; de Passillé, 2001). Postingestive signals from visceral receptors (chemoreceptors, osmoreceptors, and mechanoreceptors) are generally believed to reflect the existence of short-term mechanisms of milk intake regulation in preruminant calves (Guilloteau et al., 1997; Senn et al., 2000; Forbes, 2007). For example, it has also been observed that milk meal size in calves with free access to milk is positively correlated with the duration of the postmeal interval (Senn et al., 2000), suggesting that the amount of feed ingested influences the distribution of milk meals. Unfortunately, meal intervals were not recorded in the current study to allow more precise monitoring of the meal patterns.

In the current study, the number of total visits as well as rewarded and unrewarded visits per day at the automatic MR feeder were similar between groups (HI and LO), suggesting these calves were persistent in attempting to access MR. All calves had an increased number of unrewarded visits around the time of reduced milk delivery during the gradual weaning, suggesting a lack of satiety in these calves at wh 10 and 11 . The greater drinking speed at the automatic MR feeder in $\mathrm{HI}$ than in LO calves contributed to the greater MR meal size in $\mathrm{HI}$ calves.

Interestingly, HI calves had greater concentrate intake immediately following reduced milk intakes during weaning at wk 10 and 11 compared with LO calves. The greater concentrate intake at the end of the study in HI calves indicated that the capacity for feed intake referred to both MR and solid feed intake. The study also showed that a higher milk intake pattern is not necessarily associated with less solid feed intake, as often discussed in previous studies (Jasper and Weary, 2002; Gelsinger et al., 2016), and support the concept that an intensive milk feeding program favors solid feed intake after weaning (Khan et al., 2011). As a consequence, 
A

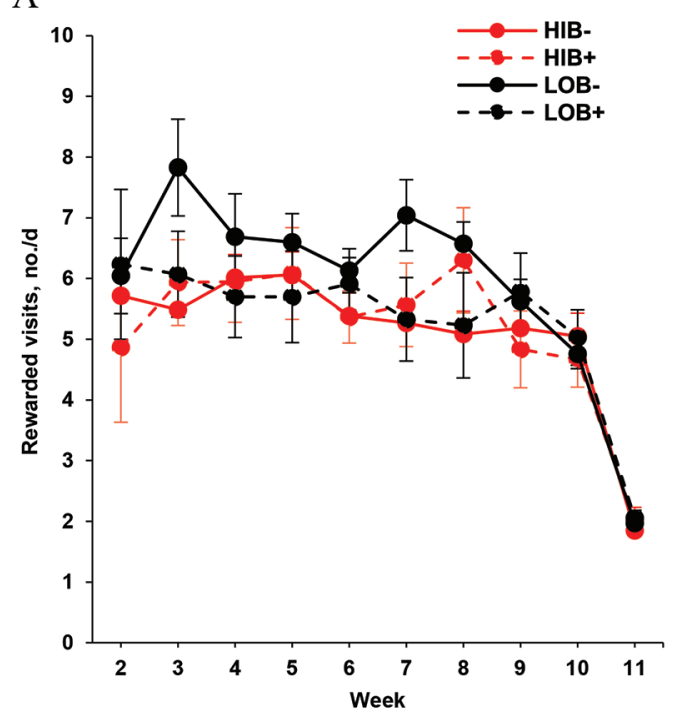

$\mathrm{C}$

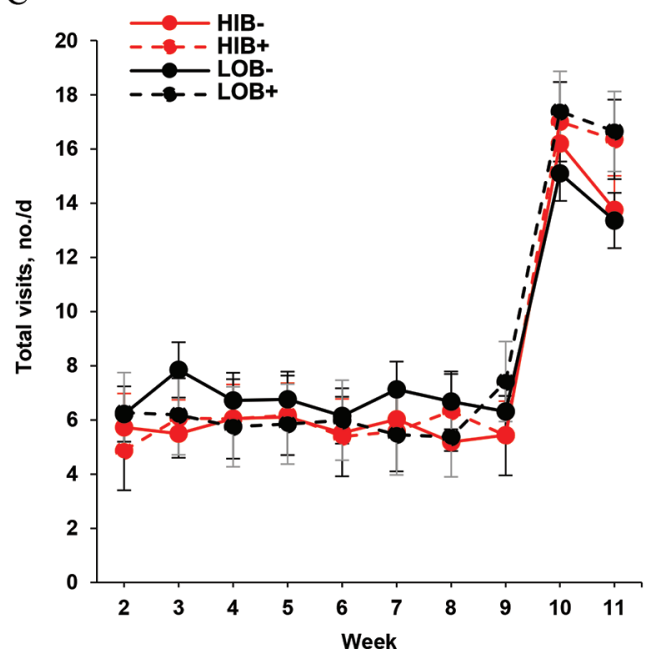

B

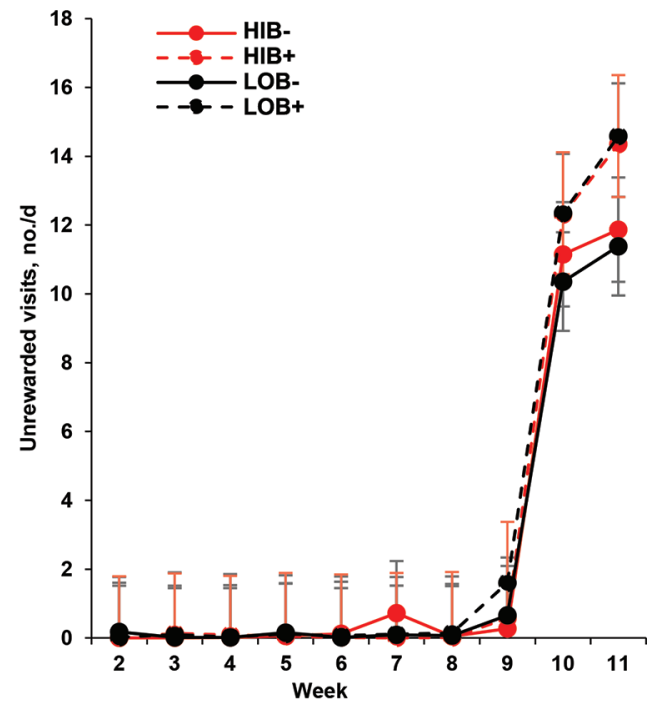

D

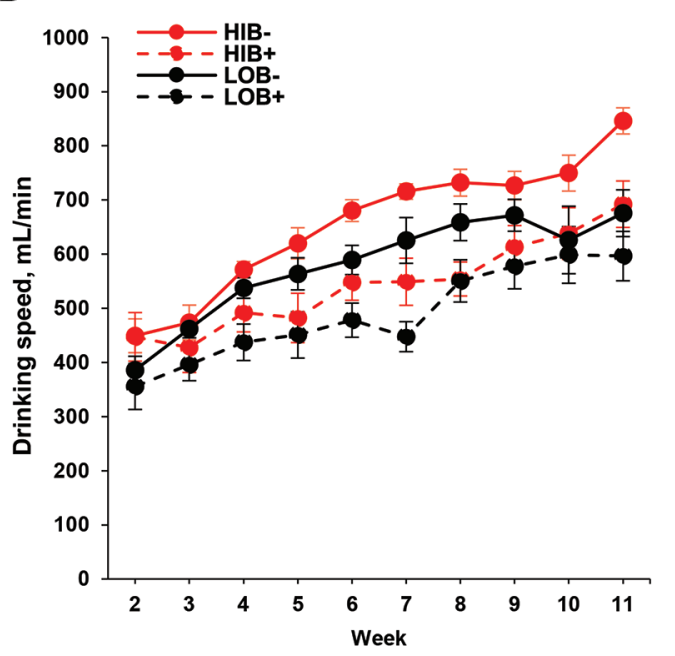

Figure 3. Feeding behavior. Rewarded visits (A), unrewarded visits (B), total visits (C), and drinking speed (D) of calves fed ad libitum milk replacer (MR) with high and low MR meal size supplemented MR without (HIB-, LOB-) or with 0.33\% calcium-sodium butyrate (HIB+, $\mathrm{LOB}+$ ). Data are presented as means $\pm \mathrm{SE}$.

this difference in MR meal size and concentrate intake resulted in a significant 105-g greater weight gain per day for the HI when compared with LO calves.

In the current study, measurements in blood plasma related to enhanced cell proliferation and growth such as insulin and IGF-I may indicate the stimulation of body growth in calves with a greater MR meal size per rewarded visit. Elevated plasma glucose concentration was found to be associated with enhanced growth in preweaning calves (Schäff et al., 2016; Frieten et al., 2017; Mirzaei et al., 2018). This is expected as HI calves received greater levels of dietary lactose and glucose intake (Frieten et al., 2017). The homeostasis of circulating glucose relies on the interplay between glu- coneogenesis and glucose utilization, as well as pancreatic glucagon and insulin production (McDowell, 1983; Brockman and Laarveld, 1986; Jones et al., 1995). In this study, the increased plasma levels of glucose in HI calves caused an increase in plasma insulin levels, as previously indicated in other studies (Daniels et al., 2008; Maccari et al., 2015; Schäff et al., 2016). Given that insulin is a key anabolic hormone and promotes body gain by encouraging stimulating the synthesis of protein and fat (Qaid and Abdelrahman, 2016), the rise in plasma insulin mirrored the stimulation of anabolic processes to support body growth to a greater extent in HI than LO calves (McDowell, 1983; Brockman and Laarveld, 1986). This finding is supported by the trend 
for elevated plasma IGF-I in HI calves because insulin stimulates the somatotropic axis, and thus systemic IGF-I (Hammon et al., 2012). In line with these results, feeding a high level of milk resulted in higher concentrations of circulating IGF-1 in preweaning calves (Bartlett et al., 2006; Daniels et al., 2008; Schäff et al., 2016). In contrast, plasma levels of IGFBP2, IGFBP3, and IGFBP4 did not respond to MR meal size in this study.

The greater protein intake from $\mathrm{MR}$ in $\mathrm{HI}$ than in LO calves might also explain the increase in plasma urea concentration. The greater MR meal size resulted in increased plasma concentrations of TP in HI than in LO calves. The elevated plasma TP concentrations in HI calves likely resulted from greater plasma concentrations of albumin and SAA. In calves, haptoglobin, SAA, fibrinogen, and albumin are the major acutephase proteins found in the circulation (Tothova et al., 2014). Acute-phase proteins are identified as either positive (haptoglobin, SAA, fibrinogen) or negative (albumin), depending on whether their blood concentrations increase or decrease in response to inflammation (Jain et al., 2011). In this study, positive (SAA) and negative (albumin) plasma concentrations of acutephase proteins were slightly greater in $\mathrm{HI}$ than LO calves. Therefore, there was no consistent relationship between MR meal size and the inflammatory status in these calves.

\section{Study Limitations}

The design of our study had some limitations, such as the relatively small sample size, and the selected clusters might not be representative of all calves with free access to MR. Therefore, the differences in the growth performance of calves might be more detectable with a larger number of replicates. The small sample size may limit the ability to generalize our findings to the accessible population or general population and may have an implication in the significance and reproducibility of the results obtained in this study. Therefore, the extrapolation of our findings to the general population is restricted.

Given the above limitations, the lack of difference in some outcomes could certainly be explained by a type II error due to the sample size. Also, the lack of accounting for clustering in these calculations could attribute to these type II errors. Nevertheless, there is not that much information on this topic available; therefore, this study presented findings by taking a

Table 4. Blood metabolites and hormones in calves fed ad libitum milk replacer (MR) as high (HI) or low (LO) per rewarded visit supplemented MR without (HIB-; LOB-) or with $0.33 \%$ calcium-sodium butyrate (HIB+; LOB+)

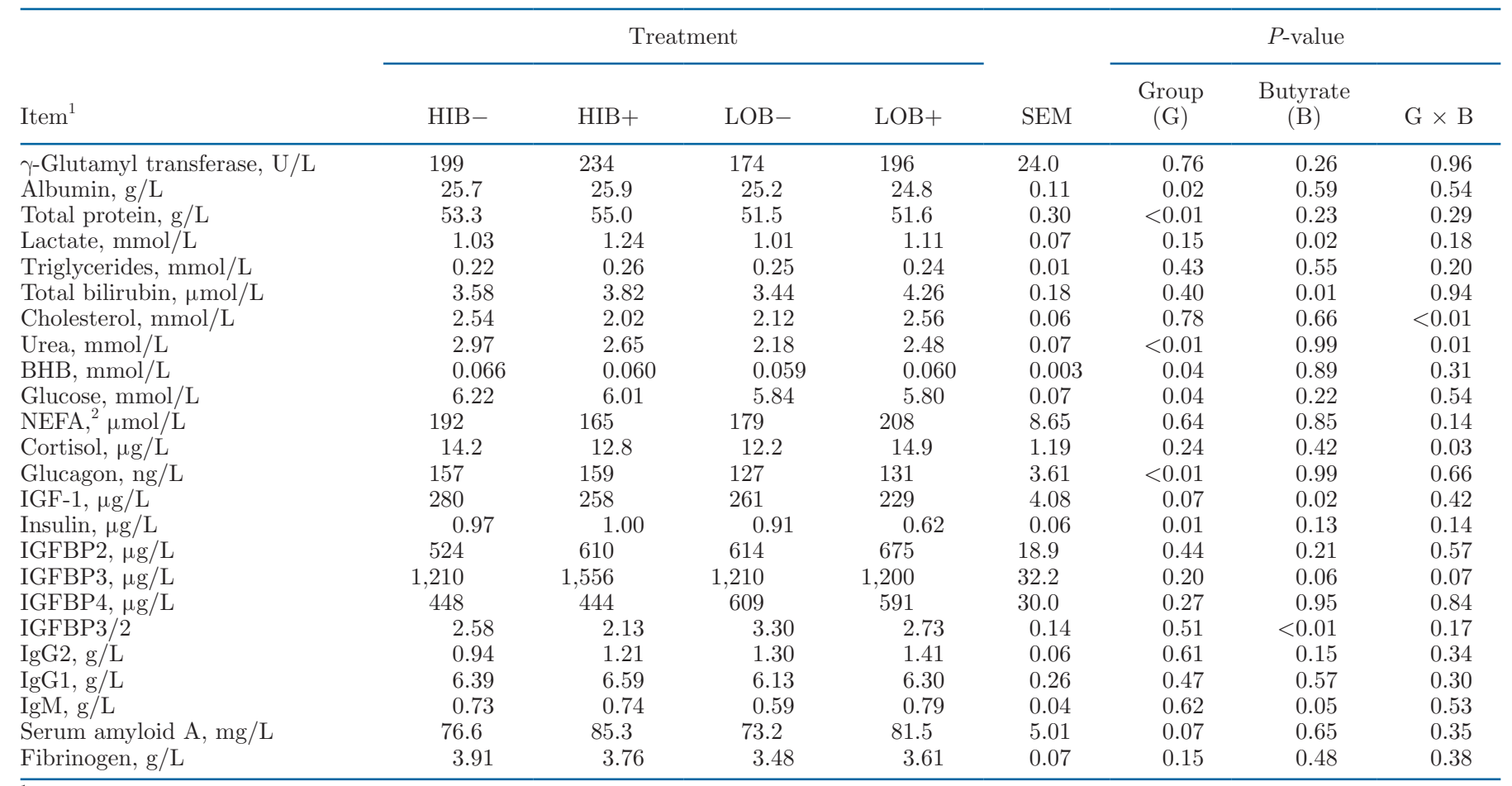

${ }^{1}$ Values are presented as LSM.

${ }^{2} \mathrm{NEFA}=$ nonesterified fatty acid. 
A



C

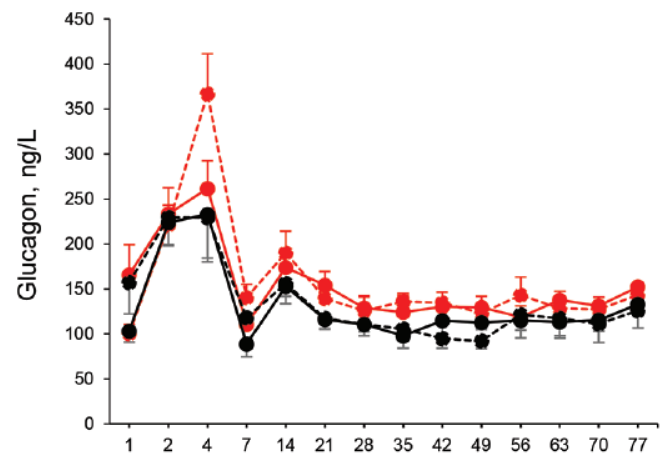

E

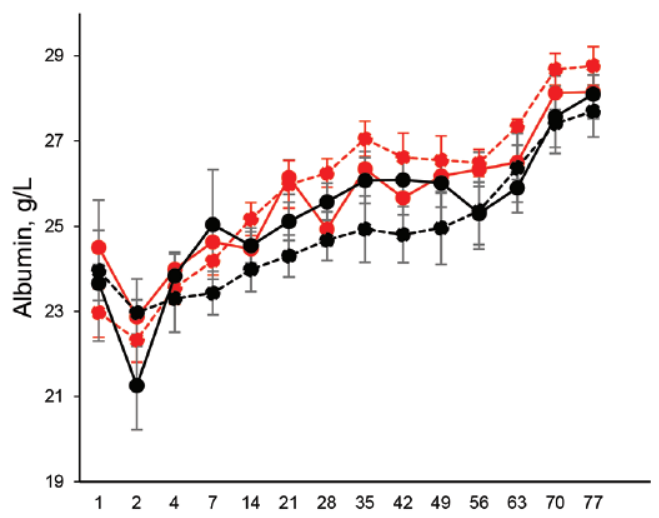

G



B

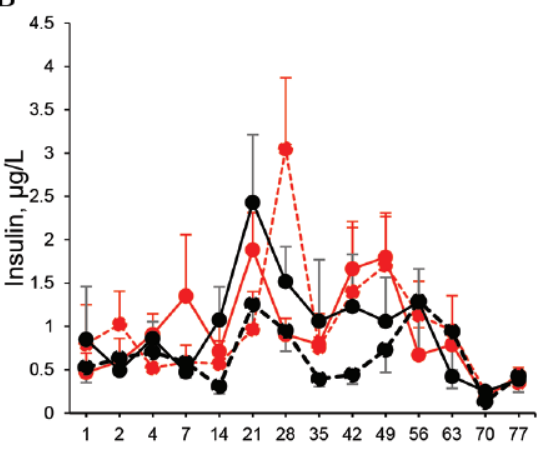

D

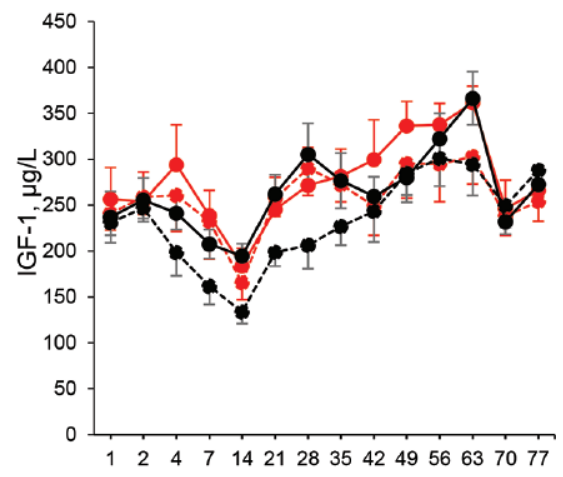

$\mathrm{F}$

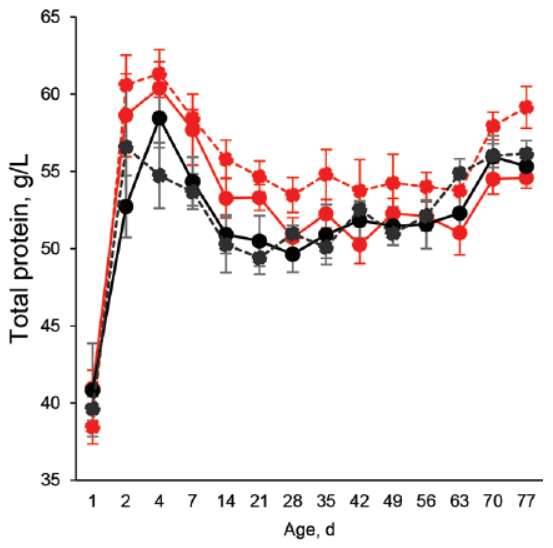

Figure 4. Blood plasma concentrations of glucose (A), insulin (B), glucagon (C), IGF-1 (D), albumin (E), total protein (F), and BHB (G) of calves fed ad libitum milk replacer (MR) with high (HI) and low (LO) MR meal size supplemented MR without (HIB-, LOB-) or with 0.33\% calcium-sodium butyrate (HIB,$+ \mathrm{LOB}+)$. Data are presented as means $\pm \mathrm{SE}$. 
longitudinal sampling approach. In that sense, future studies with larger sample sizes are required to confirm our preliminary insights.

Another limitation of the study was the fact that treatments with respect to butyrate were performed in 2 different pens, and MR with and without butyrate were provided by 2 different automatic MR feeders. We cannot completely rule out the possibility that the pens influenced the butyrate effects. Because the 2 pens were in the same stable and calves with or without butyrate treatment were investigated at the same time, the environmental and study conditions were the same for the 2 pens. In addition, both automatic MR feeders were from the same company and belonged to the same type of automatic feeders. Therefore, we assumed that confounding between pen and butyrate supplementation was at a minimum. Furthermore, butyrate treatment was not the main focus of the study. The butyrate supplementation was equally distributed between clusters and failed to affect a difference in MR meal size.

\section{CONCLUSIONS}

Although preliminary, and having only 32 calves investigated, this study implied new insights that can contribute to future studies in the field of calf behavior. Clustering analysis in our study revealed 2 clusters of animals that differed for the meal size (MR intake per rewarded visit). Larger MR meal size during the first 8 wk of age tended to increase nutrient intake and accelerated calf growth, but did not improve the final BW. A greater concentrate intake at the end of the study in HI calves indicated that the capacity for feed intake referred to both MR and solid feed intake. Measurements in blood plasma adumbrated the stimulation of body growth in preweaning calves with a greater MR meal size. Although this study highlights the considerable interindividual variation in the feeding behavior of calves with free access to MR, the design of our study had some limitations such as the relatively small sample size. We expect that this experiment will be the basis of future experimental validation of our results in a larger cohort study.

\section{ACKNOWLEDGMENTS}

Special thanks are extended to C. Reiko, B. Mielenz, U. Wiedemuth, and P. Müntzel [Leibniz Institute for Farm Animal Biology (FBN), Dummerstorf, Germany] for excellent laboratory work. We further acknowledge the quantification of IGFBP by Christine Höflich (Ligandis UG, Gülzow, Germany). We also thank the staff of the Educational and Research Centre for Animal
Husbandry (Hofgut Neumuehle, Alsenz, Germany), and the students and Animal Nutrition team at the University of Applied Sciences Bingen (Rhein, Germany). The publication of this article was funded by the Open Access Fund of the Leibniz Institute for Farm Animal Biology (FBN; Dummerstorf, Germany).The authors confirm that there are no recognized conflicts of interest associated with this publication.

\section{REFERENCES}

Appleby, M. C., D. M. Weary, and B. Chua. 2001. Performance and feeding behavior of calves on ad libitum milk from artificial teats. Appl. Anim. Behav. Sci. 74:191-201. https://doi.org/10.1016/ S0168-1591(01)00171-X.

Bartlett, K. S., F. K. McKeith, M. J. VandeHaar, G. E. Dahl, and J. K. Drackley. 2006. Growth and body composition of dairy calves fed milk replacers containing different amounts of protein at two feeding rates. J. Anim. Sci. 84:1454-1467. https://doi.org/10 $.2527 / 2006.8461454 \mathrm{x}$.

Borcard, D. 2011. Numerical Ecology with R. Springer, New York, NY.

Borderas, T. F., A. M. de Passillé, and J. Rushen. 2009. Feeding behavior of calves fed small or large amounts of milk. J. Dairy Sci. 92:2843-2852.

Brockman, R. P., and B. Laarveld. 1986. Hormonal regulation of metabolism in ruminants; a review. Livest. Prod. Sci. 14:313-334. https://doi.org/10.1016/0301-6226(86)90012-6.

Daniels, K. M., S. R. Hill, K. F. Knowlton, R. E. James, M. L. McGilliard, and R. M. Akers. 2008. Effects of milk replacer composition on selected blood metabolites and hormones in preweaned Holstein heifers. J. Dairy Sci. 91:2628-2640. https://doi.org/10.3168/ jds.2007-0859.

Davis Rincker, L. E., M. J. VandeHaar, C. A. Wolf, J. S. Liesman, L. T. Chapin, and M. S. Weber Nielsen. 2011. Effect of intensified feeding of heifer calves on growth, pubertal age, calving age, milk yield, and economics. J. Dairy Sci. 94:3554-3567. https://doi.org/ $10.3168 /$ jds.2010-3923.

De Koster, J., M. Salavati, C. Grelet, M. A. Crowe, E. Matthews, R. O'Flaherty, G. Opsomer, L. Foldager, and M. Hostens. 2019. Prediction of metabolic clusters in early-lactation dairy cows using models based on milk biomarkers. J. Dairy Sci. 102:2631-2644. https://doi.org/10.3168/jds.2018-15533.

de Passillé, A. M. 2001. Sucking motivation and related problems in calves. Appl. Anim. Behav. Sci. 72:175-187. https://doi.org/10 .1016/S0168-1591(01)00108-3.

de Passillé, A. M., P. G. Marnet, H. Lapierre, and J. Rushen. 2008. Effects of twice-daily nursing on milk ejection and milk yield during nursing and milking in dairy cows. J. Dairy Sci. 91:1416-1422. https://doi.org/10.3168/jds.2007-0504.

de Passillé, A. M., and J. Rushen. 2012. Adjusting the weaning age of calves fed by automated feeders according to individual intakes of solid feed. J. Dairy Sci. 95:5292-5298. https://doi.org/10.3168/ jds.2012-5521.

Dennis, T. S., F. X. Suarez-Mena, T. M. Hill, J. D. Quigley, R. L. Schlotterbeck, and L. Hulbert. 2018. Effect of milk replacer feeding rate, age at weaning, and method of reducing milk replacer to weaning on digestion, performance, rumination, and activity in dairy calves to 4 months of age. J. Dairy Sci. 101:268-278. https:/ /doi.org/10.3168/jds.2017-13692.

DeVries, T. J., and M. A. G. von Keyserlingk. 2009. Feeding method affects the feeding behavior of growing dairy heifers. J. Dairy Sci. 92:1161-1168. https://doi.org/10.3168/jds.2008-1314.

Ellingsen, K., C. M. Mejdell, N. Ottesen, S. Larsen, and A. M. Grondahl. 2016. The effect of large milk meals on digestive physiology and behaviour in dairy calves. Physiol. Behav. 154:169-174. https: //doi.org/10.1016/j.physbeh.2015.11.025. 
Federal Republic of Germany. 2014. Tierschutzgesetz. Accessed Dec. 4, 2017. http://www.gesetze-im-internet.de/tierschg/ BJNR012770972.html.

Forbes, J. M. 2007. voluntary food intake and diet selection in farm animals. 2nd ed. CABI, Cambridge, MA.

Frieten, D., C. Gerbert, C. Koch, G. Dusel, K. Eder, A. Hoeflich, B. Mielenz, and H. M. Hammon. 2018. Influence of ad libitum milk replacer feeding and butyrate supplementation on the systemic and hepatic insulin-like growth factor I and its binding proteins in Holstein calves. J. Dairy Sci. 101:1661-1672. https://doi.org/ 10.3168/jds.2017-13603 https://doi.org/10 .3168/jds.2017-13603.

Frieten, D., C. Gerbert, C. Koch, G. Dusel, K. Eder, E. Kanitz, J. M. Weitzel, and H. M. Hammon. 2017. Ad libitum milk replacer feeding, but not butyrate supplementation, affects growth performance as well as metabolic and endocrine traits in Holstein calves. J. Dairy Sci. 100:6648-6661. https://doi.org/10.3168/jds.2017-12722.

Geiger, A. J., C. L. M. Parsons, R. E. James, and R. M. Akers. 2016. Growth, intake, and health of Holstein heifer calves fed an enhanced preweaning diet with or without postweaning exogenous estrogen. J. Dairy Sci. 99:3995-4004.

Gelsinger, S. L., A. J. Heinrichs, and C. M. Jones. 2016. A metaanalysis of the effects of preweaned calf nutrition and growth on first-lactation performance. J. Dairy Sci. 99:6206-6214. https:// doi.org/10.3168/jds.2015-10744.

Gerbert, C., D. Frieten, C. Koch, G. Dusel, K. Eder, T. Stefaniak, J. Bajzert, P. Jawor, A. Tuchscherer, and H. M. Hammon. 2018. Effects of ad libitum milk replacer feeding and butyrate supplementation on behavior, immune status, and health of Holstein calves in the postnatal period. J. Dairy Sci. 101:7348-7360. https://doi .org/10.3168/jds.2018-14542.

Gesellschaft für Ernährungsphysiologie (German Society of Nutrition Physiology). 2009. New equations for predicting metabolisable energy of compound feeds for cattle. Communications of the Committee for Requirement Standards of the Society of Nutrition Physiology. Proc. Soc. Nutr. Physiol. 18:143-146.

Górka, P., Z. M. Kowalski, P. Pietrzak, A. Kotunia, W. Jagusiak, J. J. Holst, R. Guilloteau, and R. Zabielski. 2011a. Effect of method of delivery of sodium butyrate on rumen development in newborn calves. J. Dairy Sci. 94:5578-5588.

Górka, P., Z. M. Kowalski, P. Pietrzak, A. Kotunia, W. Jagusiak, and R. Zabielski. 2011b. Is rumen development in newborn calves affected by different liquid feeds and small intestine development? J. Dairy Sci. 94:3002-3013. https://doi.org/10.3168/jds.2010-3499.

Gruse, J., E. Kanitz, J. M. Weitzel, A. Tuchscherer, T. Stefaniak, P. Jawor, S. Wolffram, and H. M. Hammon. 2016. Quercetin feeding in newborn dairy calves cannot compensate colostrum deprivation: Study on metabolic, antioxidative and inflammatory traits. PLoS One 11:e0146932. https://doi.org/10.1371/journal.pone.0146932.

Guilloteau, P., I. Le Huërou-Luron, J. A. Chayvialle, R. Toullec, R. Zabielski, and J. W. Blum. 1997. Gut regulatory peptides in young cattle and sheep. Zentralbl. Veterinärmed. A 44:1-23. https://doi .org/10.1111/j.1439-0442.1997.tb01082.x.

Guilloteau, P., R. Zabielski, J. C. David, J. W. Blum, J. A. Morisset, M. Biernat, J. Wolinski, D. Laubitz, V. Rome, and Y. Hamon. 2009. Sodium-butyrate as a growth promoter in milk replacer formula for young mammals. J. Dairy Sci. 92:1038-1049. https://doi .org/10.3168/jds.2008-1213.

Hammon, H. M., G. Schiessler, A. Nussbaum, and J. W. Blum. 2002. Feed intake patterns, growth performance, and metabolic and endocrine traits in calves fed unlimited amounts of colostrum and milk by automate, starting in the neonatal period. J. Dairy Sci. 85:3352-3362. https://doi.org/10.3168/jds.S0022-0302(02)74423 $-8$.

Hammon, H. M., J. Steinhoff-Wagner, U. Schönhusen, C. C. Metges, and J. W. Blum. 2012. Energy metabolism in the newborn farm animal with emphasis on the calf: Endocrine changes and responses to milk-born and systemic hormones. Domest. Anim. Endocrinol. 43:171-185. https://doi.org/10.1016/j.domaniend.2012.02.005.

Hammon, H. M., G. Stürmer, F. Schneider, A. Tuchscherer, H. Blum, T. Engelhard, A. Genzel, R. Staufenbiel, and W. Kanitz. 2009. Performance and metabolic and endocrine changes with emphasis on glucose metabolism in high-yielding dairy cows with high and low fat content in liver after calving. J. Dairy Sci. 92:1554-1566. https://doi.org/10.3168/jds.2008-1634.

Hintze, J. 2008. PASS 2008. NCSS, LLC, Kaysville, UT.

Jafari, A., A. Azarfar, G. R. Ghorbani, M. Mirzaei, M. A. Khan, H. Omidi-Mirzaei, A. Pakdel, and M. H. Ghaffari. 2020. Effects of physical forms of starter and milk allowance on growth performance, ruminal fermentation, and blood metabolites of Holstein dairy calves. J. Dairy Sci. 103:11300-11313. https://doi.org/10 $.3168 /$ jds.2020-18252.

Jain, S. V. Gautam, and S. Naseem. 2011. Acute-phase proteins: As diagnostic tool. J. Pharm. Bioallied Sci. 3:118-127. https://doi .org/10.4103/0975-7406.76489.

Jasper, J., and D. M. Weary. 2002. Effects of ad libitum milk intake on dairy calves. J. Dairy Sci. 85:3054-3058. https://doi.org/10.3168/ jds.S0022-0302(02)74391-9.

Jensen, M. B. 2004. Computer-controlled milk feeding of dairy calves: The effects of number of calves per feeder and number of milk portions on use of feeder and social behavior. J. Dairy Sci. 87:34283438. https://doi.org/10.3168/jds.S0022-0302(04)73478-5.

Jensen, M. B., and M. Budde. 2006. The effects of milk feeding method and group size on feeding behavior and cross-sucking in grouphoused dairy calves. J. Dairy Sci. 89:4778-4783. https://doi.org/ 10.3168/jds.S0022-0302(06)72527-9.

Jensen, M. B., and L. Holm. 2003. The effect of milk flow rate and milk allowance on feeding related behaviour in dairy calves fed by computer controlled milk feeders. Appl. Anim. Behav. Sci. 82:87100. https://doi.org/10.1016/S0168-1591(03)00054-6.

Jones, K. L., M. Horowitz, M. J. Wishart, A. F. Maddox, P. E. Harding, and B. E. Chatterton. 1995. Relationships between gastric emptying, intragastric meal distribution and blood glucose concentrations in diabetes mellitus. J. Nucl. Med. 36:2220-2228.

Kaufhold, J. N., H. M. Hammon, R. M. Bruckmaier, B. H. Breier, and J. W. Blum. 2000. Postprandial metabolism and endocrine status in veal calves fed at different frequencies. J. Dairy Sci. 83:24802490. https://doi.org/10.3168/jds.S0022-0302(00)75140-X.

Kaufman, L., and P. J. Rousseeuw. 1990. Finding Groups in Data: An Introduction to Cluster Analysis. John Wiley and Sons Inc., New York, NY.

Kenéz, Á., C. Koch, M. Korst, J. Kesser, K. Eder, H. Sauerwein, and K. Huber. 2018. Different milk feeding intensities during the first 4 weeks of rearing dairy calves: Part 3: Plasma metabolomics analysis reveals long-term metabolic imprinting in Holstein heifers. J. Dairy Sci. 101:8446-8460. https://doi.org/10.3168/jds.2018-14559.

Khan, M. A. D. M. Weary, and M. A. von Keyserlingk. 2011. Invited review: Effects of milk ration on solid feed intake, weaning, and performance in dairy heifers. J. Dairy Sci. 94:1071-1081. https:// doi.org/10.3168/jds.2010-3733.

Kirk, J. H., B. McCowan, E. R. Atwill, K. S. Glenn, G. E. Higginbotham, C. A. Collar, A. Castillo, B. A. Reed, N. G. Peterson, and J. S. Cullor. 2005. Association of minimum inhibitory concentration cluster patterns with dairy management practices for environmental bacteria isolated from bulk tank milk. J. Dairy Sci. 88:37103720. https://doi.org/10.3168/jds.S0022-0302(05)73057-5.

Koch, C., C. Gerbert, D. Frieten, G. Dusel, K. Eder, R. Zitnan, and H. M. Hammon. 2019. Effects of ad libitum milk replacer feeding and butyrate supplementation on the epithelial growth and development of the gastrointestinal tract in Holstein calves. J. Dairy Sci 102:8513-8526. https://doi.org/10.3168/jds.2019-16328.

Korst, M., C. Koch, J. Kesser, U. Müller, F.-J. Romberg, J. Rehage, K. Eder, and H. Sauerwein. 2017. Different milk feeding intensities during the first 4 weeks of rearing in dairy calves: Part 1: Effects on performance and production from birth over the first lactation. J. Dairy Sci. 100:3096-3108. https://doi.org/10.3168/ jds.2016-11594.

Kristensen, N. B., J. Sehested, S. K. Jensen, and M. Vestergaard. 2007. Effect of milk allowance on concentrate intake, ruminal environment, and ruminal development in milk-fed Holstein calves. J. Dairy Sci. 90:4346-4355. https://doi.org/10.3168/jds.2006-885.

Kühne, S., H. M. Hammon, R. M. Bruckmaier, C. Morel, Y. Zbinden, and J. W. Blum. 2000. Growth performance, metabolic and endo- 
crine traits, and absorptive capacity in neonatal calves fed either colostrum or milk replacer at two levels. J. Anim. Sci. 78:609-620. https://doi.org/10.2527/2000.783609x.

Maccari, P., S. Wiedemann, H.-P. Kunz, M. Piechotta, P. Sanftleben, and M. Kaske. 2015. Effects of two different rearing protocols for Holstein bull calves in the first 3 weeks of life on health status, metabolism and subsequent performance. J. Anim. Physiol. Anim. Nutr. (Berl.) 99:737-746. https://doi.org/10.1111/jpn.12241.

McDowell, G. H. 1983. Hormonal control of glucose homoeostasis in ruminants. Proc. Nutr. Soc. 42:149-167. https://doi.org/10.1079/ PNS19830021.

Meale, S. J., F. Chaucheyras-Durand, H. Berends, L. L. Guan, and M. A. Steele. 2017. From pre- to postweaning: Transformation of the young calf's gastrointestinal tract. J. Dairy Sci. 100:5984-5995. https://doi.org/10.3168/jds.2016-12474.

Millar, H. R., J. Simpson, and A. Stalker. 1971. An evaluation of the heat precipitation method for plasma fibrinogen estimation. J. Clin. Pathol. 24:827-830. https://doi.org/10.1136/jcp.24.9.827.

Miller-Cushon, E. K., R. Bergeron, K. E. Leslie, and T. J. DeVries. 2013. Effect of milk feeding level on development of feeding behavior in dairy calves. J. Dairy Sci. 96:551-564. https://doi.org/10 $.3168 / \mathrm{jds} .2012-5937$.

Miller-Cushon, E. K., and T. J. DeVries. 2011. Effect of early feed type exposure on diet-selection behavior of dairy calves. J. Dairy Sci. 94:342-350. https://doi.org/10.3168/jds.2010-3382.

Miller-Cushon, E. K., and T. J. DeVries. 2015. Invited review: Development and expression of dairy calf feeding behaviour. Can. J. Anim. Sci. 95:341-350. https://doi.org/10.4141/cjas-2014-163.

Mirzaei, M., N. Dadkhah, B. Baghbanzadeh-Nobari, A. Agha-Tehrani, M. Eshraghi, M. Imani, R. Shiasi-Sardoabi, and M. H. Ghaffari. 2018. Effects of preweaning total plane of milk intake and weaning age on intake, growth performance, and blood metabolites of dairy calves. J. Dairy Sci. 101:4212-4220. https://doi.org/10.3168/jds .2017-13766.

Mirzaei, M., H. Khanaki, M. Kazemi-Bonchenari, M. A. Khan, A. H. Khaltabadi-Farahani, M. Hossein-Yazdi, and M. H. Ghaffari. 2020. Effects of step-down weaning implementation time on growth performance and blood metabolites of dairy calves. J. Dairy Sci. 103:10099-10107. https://doi.org/10.3168/jds.2020-18520.

Morris, T. R. 1999. Experimental design and analysis in animal sciences. CABI Publishing, New York, NY.

Naumann, C., and R. Bassler. 2004. Die chemische Untersuchung von Futtermittel. VDLUFA-Verlag, Darmstadt, Germany.

Neave, H. W., J. H. C. Costa, J. B. Benetton, D. M. Weary, and M. A. G. von Keyserlingk. 2019. Individual characteristics in early life relate to variability in weaning age, feeding behavior, and weight gain of dairy calves automatically weaned based on solid feed intake. J. Dairy Sci. 102:10250-10265. https://doi.org/10.3168/jds .2019-16438.

NRC. 2001. Nutrient Requirements of Dairy Cattle. 7th rev. ed. Natl. Acad. Press, Washington, DC.

Nussbaum, A., G. Schiessler, H. M. Hammon, and J. W. Blum. 2002. Growth performance and metabolic and endocrine traits in calves pair-fed by bucket or by automate starting in the neonatal period. J. Anim. Sci. 80:1545-1555. https://doi.org/10.2527/2002 $.8061545 x$.

O'Driscoll, K., M. A. G. von Keyserlingk, and D. M. Weary. 2006. Effects of mixing on drinking and competitive behavior of dairy calves. J. Dairy Sci. 89:229-233. https://doi.org/10.3168/jds .S0022-0302(06)72087-2.

Parsons, S. D., M. A. Steele, K. E. Leslie, D. L. Renaud, and T. J. DeVries. 2020. Investigation of weaning strategy and solid feed location for dairy calves individually fed with an automated milk feeding system. J. Dairy Sci. 103:6533-6556. https://doi.org/10 $.3168 /$ jds.2019-18023.

Qaid, M. M., and M. M. Abdelrahman. 2016. Role of insulin and other related hormones in energy metabolism: A review. Cogent Food Agric. 2:1-18. https://doi.org/10.1080/23311932.2016.1267691.

R Core Team. 2019. R: A language and environment for statistical computing. R Foundation for Statistical Computing. Accessed Oct. 10, 2019. https://www.R-project.org.

Rosenberger, K., J. H. C. Costa, H. W. Neave, M. A. G. von Keyserlingk, and D. M. Weary. 2017. The effect of milk allowance on behavior and weight gains in dairy calves. J. Dairy Sci. 100:504-512. https://doi.org/10.3168/jds.2016-11195.

Rousseeuw, P. J. 1987. Silhouettes: A graphical aid to the interpretation and validation of cluster analysis. J. Comput. Appl. Math. 20:53-65. https://doi.org/10.1016/0377-0427(87)90125-7.

Schäff, C. T., J. Gruse, J. Maciej, M. Mielenz, E. Wirthgen, A. Hoeflich, M. Schmicke, R. Pfuhl, P. Jawor, T. Stefaniak, and H. M. Hammon. 2016. Effects of feeding milk replacer ad libitum or in restricted amounts for the first five weeks of life on the growth metabolic adaptation, and immune status of newborn calves. PLoS One 11:e0168974. https://doi.org/10.1371/journal.pone.0168974.

Schäff, C. T., J. Gruse, J. Maciej, R. Pfuhl, R. Zitnan, M. Rajsky, and H. M. Hammon. 2018. Effects of feeding unlimited amounts of milk replacer for the first 5 weeks of age on rumen and small intestinal growth and development in dairy calves. J. Dairy Sci. 101:783-793. https://doi.org/10.3168/jds.2017-13247.

School of Veterinary Medicine. 2017. University of Wisconsin-Madison, Calf health scoring chart. Accessed Jan. 20, 2012. https:// www .vetmed.wisc.edu/dms/fapm/fapmtools/8calf/calf_health__scoring_chart.pdf.

Senn, M., S. Gross-Lüem, H. Leuenberger, and W. Langhans. 2000. Meal patterns and meal-induced metabolic changes in calves fed milk ad lib. Physiol. Behav. 70:189-195. https://doi.org/10.1016/ S0031-9384(00)00253-5.

Soberon, F., E. Raffrenato, R. W. Everett, and M. E. Van Amburgh. 2012. Preweaning milk replacer intake and effects on long-term productivity of dairy calves. J. Dairy Sci. 95:783-793. https://doi .org/10.3168/jds.2011-4391.

Soberon, F., and M. E. Van Amburgh. 2017. Effects of preweaning nutrient intake in the developing mammary parenchymal tissue. J. Dairy Sci. 100:4996-5004. https://doi.org/10.3168/jds.2016-11826.

Tothova, C., O. Nagy, and G. Kovac. 2014. Acute phase proteins and their use in the diagnosis of diseases in ruminants: a review. Vet. Med. 59:163-180. https://doi.org/10.17221/7478-VETMED.

Tremblay, M., M. Kammer, H. Lange, S. Plattner, C. Baumgartner, J. A. Stegeman, J. Duda, R. Mansfeld, and D. Dopfer. 2018. Identifying poor metabolic adaptation during early lactation in dairy cows using cluster analysis. J. Dairy Sci. 101:7311-7321. https:// doi.org/10.3168/jds.2017-13582.

Van Amburgh, M. E., and F. Soberon. 2013. The role of calf nutrition and management on lifetime productivity of dairy cattle. Pages 178-197 in Cow Longevity Conference, Hamra Farm, Tumba, Sweden. DeLaval International AB, Tumba, Sweden.

Welboren, A. C., L. N. Leal, M. A. Steele, M. A. Khan, and J. MartinTereso. 2019. Performance of ad libitum fed dairy calves weaned using fixed and individual methods. Animal 13:1891-1898. https:/ /doi.org/10.1017/S1751731119000181.

Zhang, Y. Q., D. C. He, and Q. X. Meng. 2010. Effect of a mixture of steam-flaked corn and soybeans on health, growth, and selected blood metabolism of Holstein calves. J. Dairy Sci. 93:2271-2279. https://doi.org/10.3168/jds.2009-2522. 